- 2 bist

1
$y$

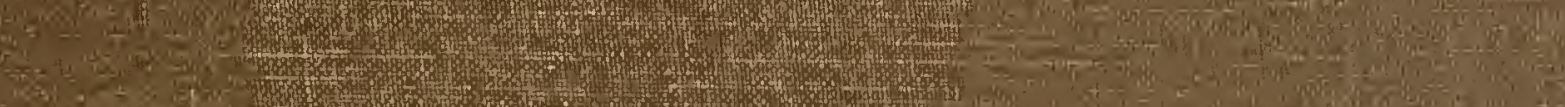
1
6

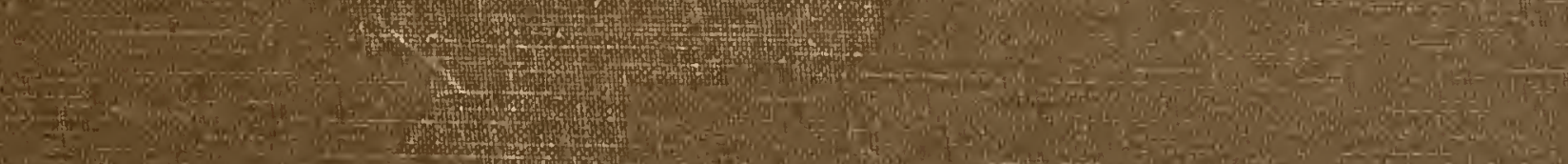
(1) $=9$ (5) $-$

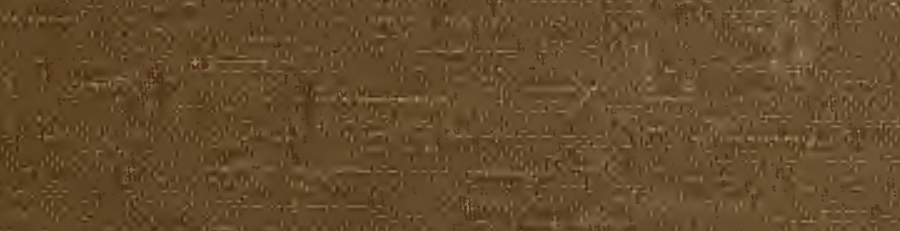

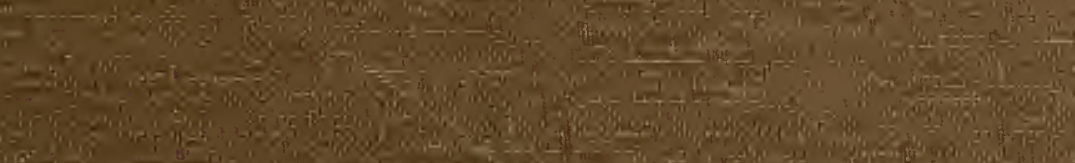

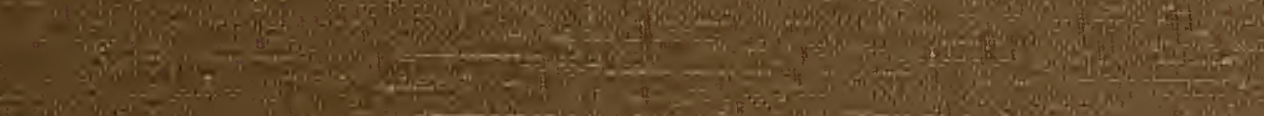

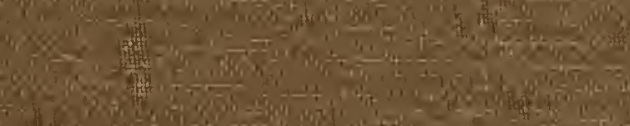
$=$

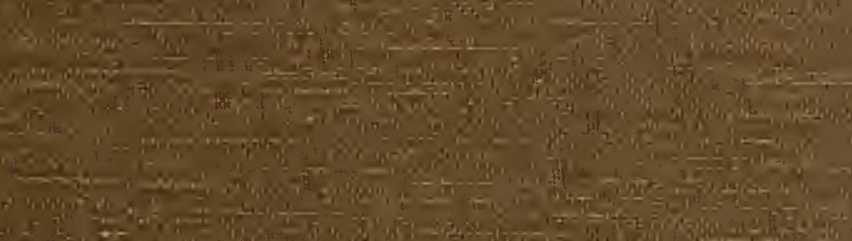

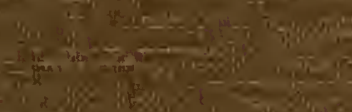

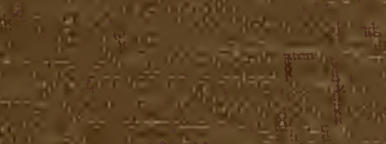
$\sqrt{25}=$

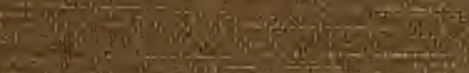

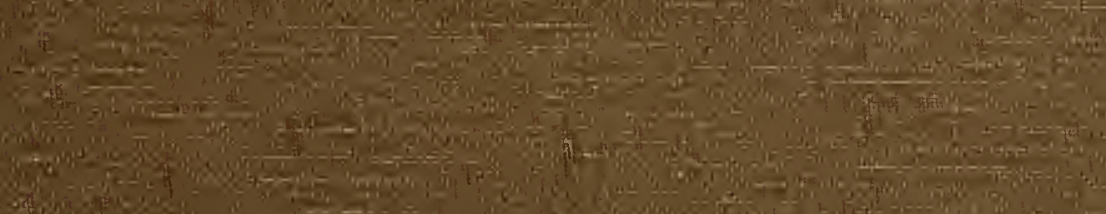
$x-5-2 x-5$

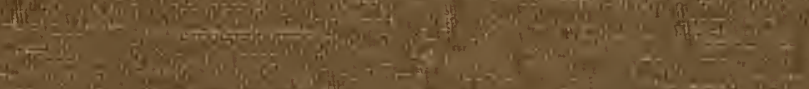
$x^{2}$ $+\frac{1}{2}$ 두너에 $2=$

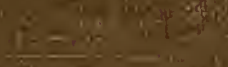

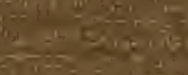
27. $=6$.

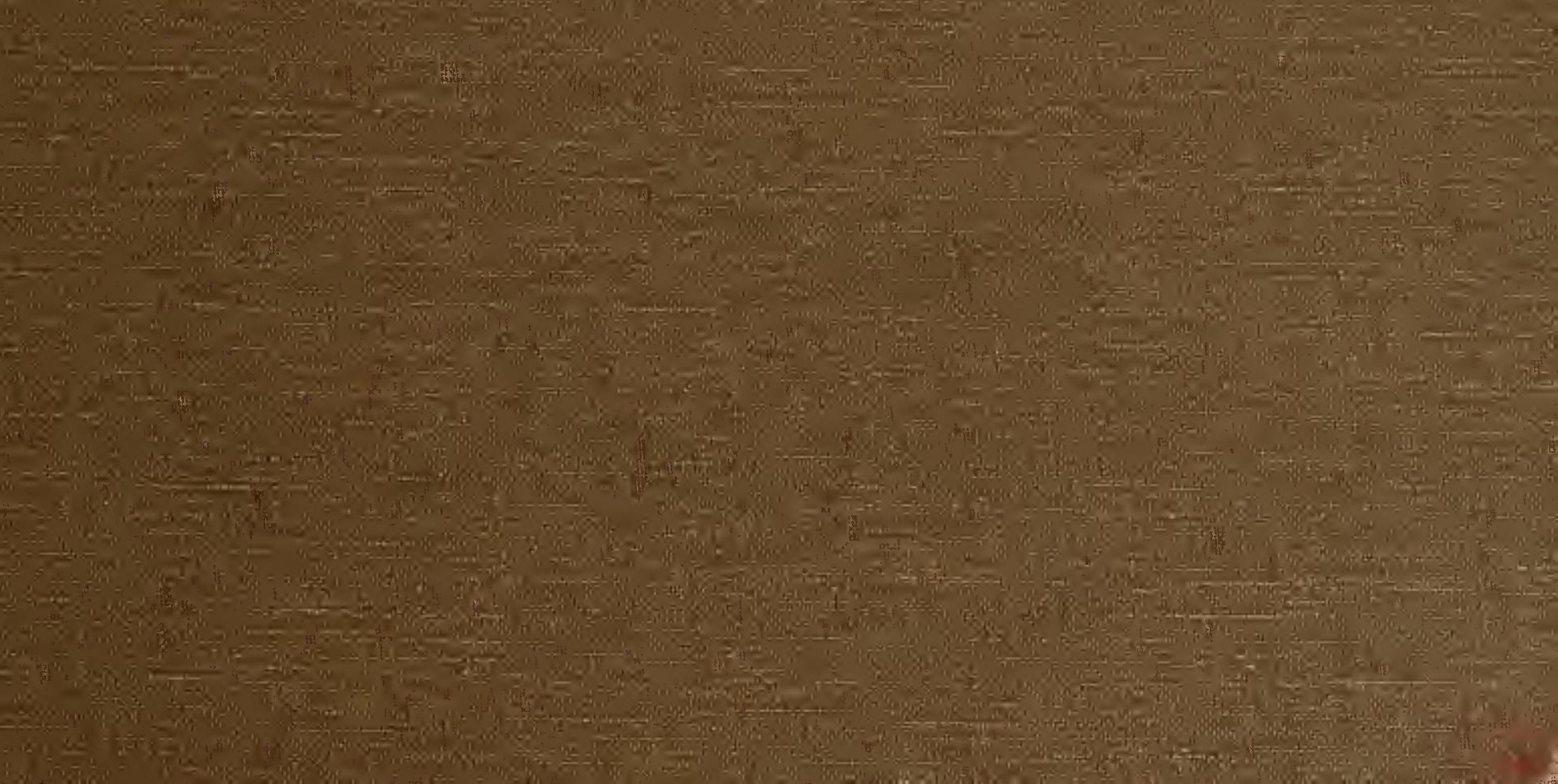




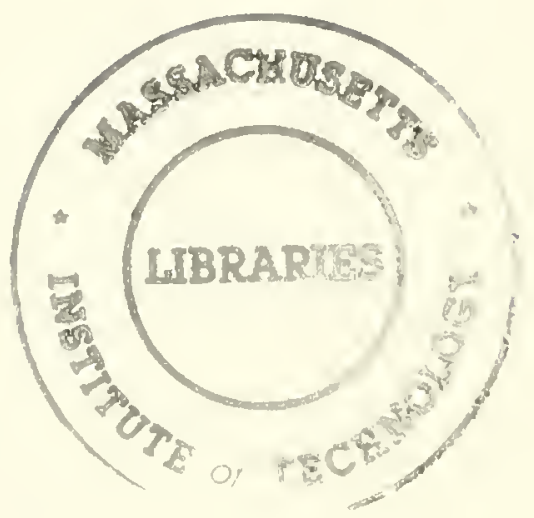




Information Technology and Work Organization

Kevin Crowston Thomas W. Malone

90s: $87-040$

\section{Working Paper}

\section{Management in the 1990 s}

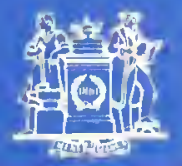

Massachusetts Institute of Technology Sloan School of Management 


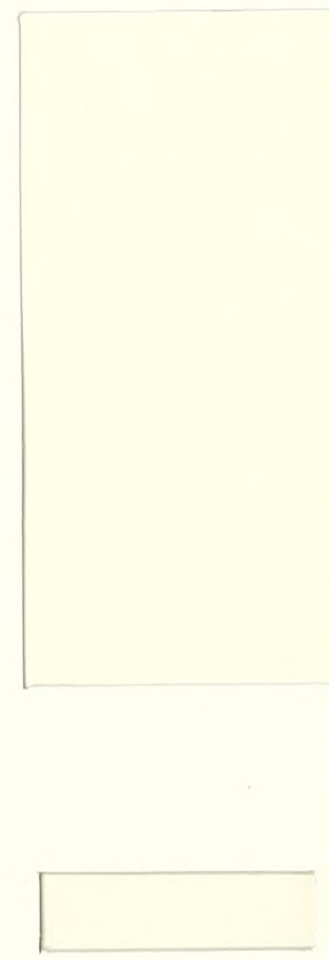


Information Technology and Work Organization

Kevin Crowston

Thomas W. Malone

90s: $87-040$

October 1987

Sloan WP \#1960-87

- Kevin Crowston

Thomas W. Malone

\author{
Management in the 1990 s \\ Sloan School of Management \\ Massachusetts Institute of Technology
}


, 
Management in the 1990s is an industry and governmental agency supported research program. Its aim is to develop a better understanding of the managerial issues of the 1990s and how to deal most effectively with them, particularly as these issues revolve around anticipated advances in Information Technology.

Assisting the work of the Sloan School scholars with financial support and as working partners in research are:

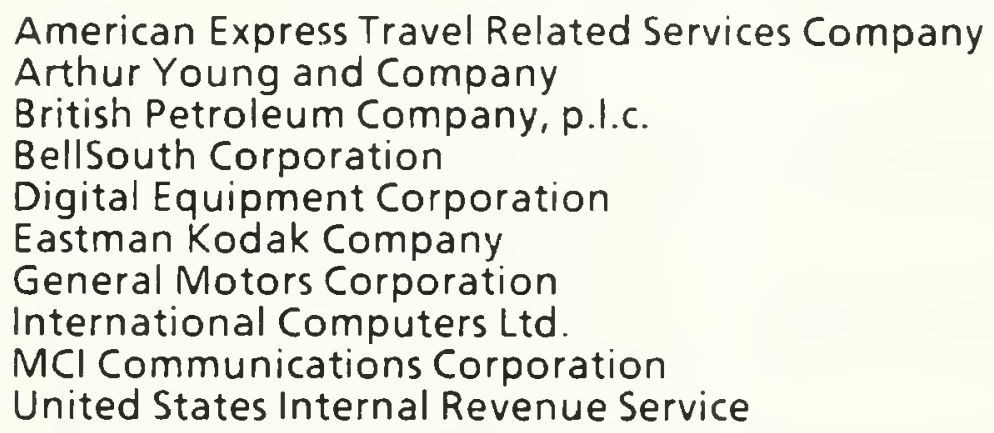

The conclusions or opinions expressed in this paper are those of the author(s) and do not necessarily reflect the opinion of Massachussetts Institute of Technology, Management in the 1990 s Research Program, or its sponsoring organizations. 


\title{
Information Technology and Work Organization
}

\author{
Kevin Crowston \\ and Thomas $W$. Halone \\ MIT Sloan School of Management
}

28-Aug-87 170708 by kgc

\section{Introduction}

Ever since at least 1958, when Leavtt and Whisler (1958) predicted that the use of information technology (IT) would lead to the demise of middle management, researchers have speculated about the impacts of IT on organizations Even though many of the early predictions have not occurred, new kinds of information technology are now increasingly affecting how people work, often in ways that we are just beginning to understand As the cost of the underlying technology continues to drop, IT is almost certain to become more and more pervasive, and may even make possible new kinds of work organization that we can as yet only bartivimagine

In this chapter, we discuss the relationship between the use of IT and work organizations. We first review theories that can help analyze organizations, technology, and the link between the two. We suggest four perspectives on uranizations-rationalist, information processing, motivational and political-which can be used to interpretorganizational structure. L'sing these four perspectives, we review the results of empirca! tudirs ol the use of $1 T$ to suggest what changes have been seen in the

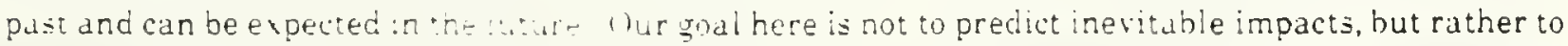
suggest possible outcomes, both and ind had. and to illuminate the factors that may lead to their 
outcomes In many cases we believe that the results of using IT are not tixed, but can instead be greatly influenced by conscious choice. We will conclude with some suggestions about the kinds of future research that will be useful and by drawing implications for the design of systems, work and organizations

\section{Theoretical Bases}

We begin our investigations by presenting three components of the theoretical basis for studies of the effects of IT on organizations. First, we need some theory about organizations that describes their important features and suggests which features will reflect the use of IT Second, we need a body of theory about technology, again to identify the features of IT that are important to its use in organizations. Finally, and perhaps most importantly, we need to somehow draw a link between some parts of these two bodies of theory. These theories are necessary for both research and practice. For research, a strong theoretical basis is necessary to suggest the important attributes of the items of interest, and to identify linkages that need to be investigated For practice, a good theory summarizes a body of research and provides implications to guide the design of new systems.

The theories in these three areas, however, are social theories, which differ from theories in sciences such as physics. This is due partly to the relative youth of the social sciences, but largely to differences in the objects of study. With social phenomena more than with many physical phenomena, there are often a large number of factors, any of which may be impurtant While many theories do make specific predictions about outcomes, a perhaps more important function is to suggest which of the many possible factors are the important ones. In this latter sense, consistent sets of these theories can be grouped together into perspectives Different perspectives suggest different hey issues. they. complement, rather than contradict ne ungher Before examining the results of past studies, then, we wll briefly discuss various perspec.......n nganıztions, technology and the : ink between the two. 


\subsection{Perspectives on organizational structure}

Obviously there are many kinds of organizations, and different kinds of organizations will be differently affected by the use of IT To reduce the scope of this chapter somewhat, we have focused our attention on formal work organizations. especially corporations Even so, there is a tremendous diversity, and unfortunately. we do not know which differences matter most. At some level, we do not really know what organizations are, and our intuitue notions are difficult to make precise. For example, task (what the organization does) is clearly important. Organizations in information-intensive industries such as insurance or banking should be quicker to show the effects of the use of IT, since computers are particularly useful for processing large quantities of information. Identifying task as a dimension, however only partially addresses the problem, unless we can next identify the important dimensions of tasks

The body of theory in this area, which should describe the important dimensions of organizations, is not very well developed or coherent. There are many partial theories of organizations that may be part of a more comprehensive theory, but these components are not yet well integrated, nor well supported empirically. Different studies have often used incompatible definitions of the same key variables, making their results difficult to compare. These differences are due partly to the exploratory nature of many of these studies. and partly to the different perspectives researchers have of organizations, reflecting the interdisciplinary nature of the field (Pfeffer, 1982) and the prior theoretical commitments of the researchera (Hir ichheim, 1986). For example, Hirschheim claims that researchers who are optimistic about the elfects of the use of IT are more likely to consider IT as a tool and to adopt what he calls a functionalist paradigm. These researchers view the world as composed of immutable objects and concentrate on destuping causal explanations of observed phenomena. Pessimists, by contrast. are more likels to "1ew IT in its social setting, adopting an interpretlint 
paradigm These researchers see the world as a social construct and attempt to understand their

findings in the framework of their subjects, rather than building causal models. Each perspective leads researchers to examine different phenomena and variables. Studies based on different assumptions about organizations have often talked past each other and focused on different features of the organizations studied. In particular, interpretivists often choose to perform detailed case studies to understand how users come to understand the technology they use and how it fills their social needs

A number of authors have suggested ways of classifying the perspectives. Pfeffer (1982) suggests two dimensions: perspective on action and level of analysis. Pfeffer first suggests that an organization's actions can be viewed in three wass, as either purposeful $($ e.. intendedly rational), externally: constrained (e.g., by a lack of some resource) or emergent (e g. random but retrospectively rationalized).

Pfeffer then distinguishes between theories that treat organizations as the units of analysis leg., market economics) and those that examine the subunits that compose organizations. Given our interest in the effects of IT on organizational structure. we will focus mainly on the latter set of perspectives. Here we can distinguish between perspectives that examine characteristics of the subunits, such as the level of skill required for a particular job, or how much autonomy a worker has in performing a task, and those that treat features of the organization as a whole. such as the arrangement of the divisions or the patterns of communication within the firm.

Kling (1980) gives six perspectives. divided into two groups which he calls systems rationalist and segmented institutionalist. Research hased in the systems rationalist perspective sees organizations as directed toward some common goal. iuch as increased efficiency or profit, and views as legitimate the authority of managers in higner le:th of the $\mathrm{irm}$ to decide tow to achieve these goals. In this perspective. IT is simply a tool that can be used to further some organizational goals. The segmented 
Institutionalist perspective, by contrast, examines the use of computing more broadly It acknowledges the effects of the technology on individuals and groups other than the actual users of the technology, and recognizes their possibly contlicting interests

In this chapter, we will discuss the effects of IT on organizations drawing on theories from four complementary perspectives proposed by Malone 119851 rattonalist. information processing, motuational and political. The irst three of these perspectives correspond roughly to the three Kling $11980)$ calls systems rationalist. The rationalist perspective assumes that organizations are composed of intendedly rational agents, operating towards some defined goal, typically profit maximization. It focuses on economic efficiency and rationally structuring the firm. The information processing approach shares many of these characteristucs. but focuses instead on the organizational processes and communications patterns of the tirm The motivational perspective recognizes that workers may have different interests than the management of an organization, but typically assumes that these goals can be matched by properly designing the jobs of individual workers If a job is sufficiently motivating. workers will presumably be more satisfied and will want to perform well. The political view is one example of Kling's segmented institutionalist perspectives It assumes that different groups within the organization may have conflicting goals that can not be reconciled. Power determines which group achieves its goals, and IT may be used as a means to increase power

Each perspective suggests a different approach to the study of IT and organizations, and makes different predictions about the effects likely to be encountered. For example, Robe: (1981) notes that a rationalist view of organizations expects the use of IT to be associated with changes to the organization, since IT allows work to be done in new and different ways. A political view expects that IT will he used by those with power in the organization to support their position, reinforcing rather than changing the structure Some perspectres mal be mote ustul than others for analyzing the 
effects of the use of IT For example, it is unclear how the use of an electronic mail system will affect the distribution of power in a firm: it may concentrate or disperse it. It is clear, however, that the use of electronic mail will facilitate and reduce the cost of some types of communications, suggesting an information processing based analysis.

\subsection{Perspectives on technology}

The second necessary basis for the study of the impacts of IT on organizations is some theory about technology. Our ability to develop technology itself is probably more advanced than our theories about organizations, but our understanding of the uses of technology is probably behind our understanding of organizations. It is still very difficult to identify the relevant dimensions of technology or to measure it, although it is clear that there are large differences between, for example, personal computers and mainframes. The task to which the IT is applied also makes a huge difference. For example, a payroll system has greatly different functions and is likely to have different effects than an electronic mail system. Few researchers, however, have attempted to characterize IT precisely, or even to define it. Many studies have used very blunt measures of IT (such as total dollar investment in IT), and as vet there are no good typologies of different kinds of systems. Several have been proposed, but they are either too blunt to usefully distinguish different uses of technology (e.g, Bakos, 1985), or focus exclusively on technical details, omitting use altogether (e.g., Barett and Konsynski, 1982). Similar problems have been noted for studies of technology in general (e g., Fry, 1982)

Some preliminary characterizations ol technology have been made. Markus and Robey (in press) note that past researchers have identified such dimensions as batch processing versus interactive systems, decision support versus decision making systems, and administrative versus technical systems. Robey. 19831 differentiated between adminstrative systems, production scheduling systems and centra! coordination systems, and Found that different systems had differenteffects For example, he observed 
that systems designed to simply automate exısting procedures tended not to lead to any organizational changes

Past studies of IT have viewed it in different ways. Harkus and Robey (in press) identify three different conceptions of IT First. a researcher can simply measure IT as an independent variable, and attempt to correlate its use (and perhaps other factors) with organizational changes. Alternately, IT can be analyzed as a special hind of production technology For exampie, some researchers le.g., Woodward, 1980: Perrow, 1979/ have suggested ways in which an organization's structure depends on the nature of the technology it uses. Findlly, the use of IT may be an alternative organizational design strategy. For example, Galbraith (19i+197T) suggests ways in which an organization can increase its information processing capacity, including through the use of IT.

One distinction we will make is between the use of IT as a production technology and as a coordination technology. IT can be used as a production technology, to directly produce some output, for example, by producing account statements in a bank, by keeping track of policy holders in an insurance company or controlling a machine tool in a factory. These uses should be distinguished from the use of IT as a coordination technology, for example, by providing the data necessary to more closely integrate two stages in a production line or to better make some decision.

\subsection{The link between structure and technology}

The final necessary component of a thenretical basis for research in this area is a link between some aspects of the two bodies of theory outined above Lniortunately, few past studies have been explicit about the nature of the lint they were drawing. Markus and Robey (in press) discuss three different kinds of links that have been used $r, 2, t^{*}$ retarch the technological imperative, the organizational imperative and the interactiontot pet - pectib 
Technological imperatue The technological imperative assumes that the technology will have some determined effects on the structure of the firm (see Figure 1) For example, Woodward (1980) found that formality of the structure of a company seemed to depend on the type of production technology used: job shops using unit production were relatively informal. mass production companies were much more formal and continuous flow production companies were again informal The focus of research is predictive, in that it attempts to predict what changes will occur in response to the use of IT

This view can be somewhat adapted by assuming that the effects of IT are contingent on other factors, such as the environment of the tirm. There are, however, many possible other factors that need to be examined. For example, Leavitt and Whisler (1958) hypothesized that different groups would be differently affected because they differ in ease of measurement of outcomes, economic pressures and acceptance of programming of jobs.

Organizational imperative A second view . Harkus and Robey call the organizational imperative. This view reverses the direction of causality by assuming that managers make organizational changes (including adopting certain kinds of $(T$ ) in response to certain organizational needs (see Figure 2 ). Markus and Robey describe this view as prescriptive, since most authors have attempted to suggest what IT a manager should use under different conditions. For example. Galbraith (1974, 1977) gives four methods to increase organizational information processing capacity. This view focuses on the intentions of managers, however, ignoring possible unintended side effects of the use of IT. It also discounts possible non-rational goals for using IT. such as increasing political power. Furthermore, such studies have only mixed empırical suppurt. For example. Child (?) found no conclusive evidence that organizations with different forms performed differently under the same conditions.

Interactionst perspectue A Inal ate -uggested by Marku= and Rohey is an interactionist perspective, which holds that the result ot the use of IT is a conplev interaction between what the 
technology allows and what the organization and the managers want (see Figure 3). They point out that unlike the other perspectives, this view does not allow predictions about the effect of IT. In fact, they claim that this view shuns prediction for understanding the underlying reasons for a change, leading to a focus on post hoc analyses. Such an approach may, however, be most appropriate for studies of complex organizations, which are affected in many ways besides by technology.

We take a modified interactıonist point of vew We helieve that in many cases IT acts an an enabling factor that makes certain kinds of organizational change possible. If those changes are desirable, they may then occur. Certain kinds of change may be especially desirable, and thus especially common, but different effects are still possible. Kling (1980) expresses a simılar view, noting that IT does not have deterministic impacts, but rather common impacts that may differ under different conditions, depending on the particulars of the organization being studied, the way the technology is used, and, perhaps most importantly, on the goals of those using it. Rather than attempting to predict changes due to particular systems, then, we hope to suggest conditions under which different uses of technology are likely to be desirable.

\section{Survey of Empirical Research}

Our aim in studying past research is not to predict what must happen, but rather to illuminate possible outcomes, including some that may not usually be considered, and to suggest the factors that lead to these outcomes. To do this we will present a variety of scenarios as examples of possible changes. In each case we will attempt to tell a plausible story about how the IT had the effect observed.

As a basis for this presentation we wil! draw on a number of different kinds ot evidence First, this subject has been a source of much interest und coverage in the popular business presi These articles 
describe the experiences of specific tirms. and provide a number of interesting examples of effects that

IT could have. On a more rigorous theoretical level is a long tradition of studies of the links between different kinds of production technology and aspects of organizational structure. A number of writers have summarized this body of literature (Fry, 1982) and we will attempt to determine where these findings are applicable. Finally, there are many studies of the impact of IT in particular, and some summaries of this body of research (Attewell and Rule, 1984. Robey, 1981. Rice, 1980)

Unfortunately, this body of literature has several limitations that make it difficult to draw general conclusions. First, the findings are mostly out of date. most of the studies are more than five years old, and the data they draw on are older sull These studies examine traditional applications such as payroll systems, while the technology has rapidly advanced. There are few studies that investigate the use of technologies such ds personal computers or electronic mail, even though these kinds of applications are likely to have enormous and quite different impacts. Second, it is difficult to generalize from these earlier studies because they were often quite vague about how the technology was actually being used. This makes it difficult to trace out the mechanism through which some application affected the firm. Finally, the methodologies employed were sometimes weak, making the strength of the conclusions questionable.

Studies of the organizational effects of IT have viewed IT and organizations in different ways and many effects have been noted Each organizational pespective suggests different kinds of effects that should be studied. To organize our survey, therefore, we have grouped the effects based on the four perspectives discussed above (see Table l' Sume effects (such as centralization) have been widely studied, however, and we will survey these issues from multiple perspectives.

\subsection{Rationalist perspective}


In this section we will draw mainly from classical organization theory, with its focus on rationality and efficiency. We will consider several features of organizations suggested by this perspective. First. we will examine a number of interrelated aspects of the level of employment. Second, we will consider centralization, specifically, changes in the locus of organizational decision making We will conclude by briefly discussing two other structural leatures: the degree of specialization and differentiation between jobs and the overall degree of formalization in the firm

\subsubsection{Employment}

Organizations differ in size, and intultively we expect different size organizations to behave differently. Differences in size are rellected in several interrelated measures, including the number of employees, the number of levels of management in a hierarchical organization, the number of employees reporting to a specific manager (the manager's span of controll, and the ratio of production workers to administrat've workers in a firm (the firm's administrative intensity). Obviously, these features are interrelated, and a change to the structure of an organization may affect a combination of them. For example, a firm may reduce its head count either by eliminating some employees from all parts of the organization, reducing the number of employees reporting to a single manager, or even by eliminating an entire level of management

Studies of these aspects of size have not found consistent results. This is partly because there may be no general effects. In addition, however, past studies have often treated these various factors independently, making it difficult to see any more general patterns. In addition. different uses of IT have not been separated, further clouding the issue, since the actual effect seems to depend heavily on how the technology is used In this section, we will differentiate between the use of IT for production and tor coordination functions 
An early common prediction was that widespread use of IT would replace most routine workers, thus causing massive unemployment le g. Myers, 1967. Mumford, 1967), and in fact, systems have often been cost justified on the basis of reductions in numbers of employees (e g.. Watteis, 1979). For instance, Rice (1980) cites a study of 33 companies (Sanders, 1977) in which 90\% reduced employment cone laying off thousands of workers) or increased output with the same staff. The prediction of an overall reduction in employment due to the use of IT is difficult to support empirically, however, as most studies have been cases, examining only a few'firms or a few industries, and more comprehensive census data are difficult to interpret unequivocally (Attewell and Rule, 1984). Furthermore, other factors may more strongly affect emplos ment, masking the effect of the use of IT.

In fact, it is interesting to note that IT may, in some cases, increase rather than decrease employment. For instance, Osterman (1986) suggests several means by which the use of IT may affect clerical employment. First. computers might be used simply to replace clerks Second, the use of IT may itself create some new jobs, such as data entry clerks, or positions in the data processing department. Third. the use of computers may make the firm more efficient, increasing the demand for its products and thus indirectly its total level of employment. Finally, coordination may be viewed as a complementary input in the production process. For instance, if IT makes coordination more effective and less expensive, the demand for coordination and therefore for both IT and the clerks who provide it may increase. This analysis holds only for coordination functions, however. suggesting that clerks employed in production function = are mure likely to be displaced by the use of IT. The total effect of the use of IT on the employment of managers may be less, since fewer managers are involved in production rather than coordinatwn functions ()iterman combined these elfects in a microeconomic production function, and attempted ris culculte the rate of substitution between clerks and conputers. 
Lsing census data from 1970 through 1978, he found that the use of computers initially led to decreased employment, but that this effect was partially offset by a subsequent increase in employment due to increased amounts of coordination. As he points out, however, this later increase may involve a different set of workers than were initially displaced

\subsection{3 . Administrative intensity}

The jobs of most managers are so far less affected by automation of production functions than those of clerks. In this case, the decreased numbers of production workers and unchanged number of managers and other coordination workers indicaten that the administrative intensity the ratio of administrative to production workers may actually be increased by the use of IT to automate production functions. Osterman also suggests that the use of IT will affect the jobs of workers in production more than those in coordination functions, again increasing administrative intensity. A number of studies are consistent with this general prediction For instance, Stabell and Forsund (1983) found that increased use of computers is associated with higher levels of administrative intensity. Scharek and Barton (1975) note a reduction of low level personnel. Whisler (1970a) found the companies he studied reduced the number of clerical employees they employed, but the supervisory and managerial levels stayed about the same. Blau et al. (1976) and Rice (1980) also note a raised proportion of professionals and Business Week (1984) describes a firm that changed from $70 \%$ clerical to $60 \%$ professional, with an overall reduction of $20 \%$. Zuboff (1983b) and Volan and Pollock (1986) describe this change graphically as a shift from a triangular hierarchy to a diamond shaped firm, thicker in the middle than at the bottom or top.

$3.11+$ Levels of hierarch: 
One of Leavitt and Whisler's (1953) original predictions is that the number of levels of hierarchy in organızations will decrease as computers are used to perform the functions of those middle managers So far, however, there is no conclusive evidence that this prediction has been realized. Changes in levels of hierarchy seem to depend heavily on the way the IT Is used, and different studies have reported opposite findings Business Week (1984), for example, discusses firms that are replacing bureaucratic functions with computers and thus trimming the number of levels of hierarchy Also. Crowston, Malone and Lin (in press) studied the use of a computer conferencing system used to help eliminate a level of hierarchy They found, however, that new central staff specialist positions were created at the same grade level as those eliminated, leaving the total employment approximately unchanged. Whisler (1970a) found little evidence of changes in hierarchical levels in his studies, but noted one case where the number of levels increased at the upper level and decreased at the lower level, keeping the total the same Blau el al. (1976) hypothesized that IT could actually increase the levels of hierarchy, since it could be used as an impersonal means of control, and shorten the feedback loop even if the number of levels is increased. Similarly. Pfeffer and Leblebici (1977) found that the use of IT as a means of control led to more levels of hierarchy and more departments when controlling for the size of the firm

\subsection{Centralization and decentralization}

Centralization is perhaps the mostly commonly investigated organizational effect of the use of IT. When this literature is examined. however, it becomes apparent that the concept of centralization has been variously defined and the effect of IT will differ depending on which construct is examined. We will examine mainly centralization or decentralization of decision making Even so, IT may affect decisions differently, simultaneously causing both centralization and decentralization. 
We can think of the use of $1 \mathrm{~T}$ as a means of reducing the cost of coordination. This often seems to lead to increased centralization, but this effect is not inevitable. We will examine two kinds of reasons-economic and motivational-for why an organization might choose to either centralize or decentralize and we will suggest how cheaper coordination can aid either process

\subsection{1 . Economic reasons}

Reduction of buffer inventorles. One motive for centralizing is the reduction of buffer inventories between groups by more tightly coordinating their interaction (e.g, "just-in-time" inventories). This closer integration often requires some decisions to be made at a higher level and implemented by each group In some cases. IT is used explicitly for coordination. For example, production scheduling systems attempt to more closely coordinate deliveries of raw materials with their use, thus requiring closer cooperation between the purchasing and production departments. Argyris $(1970)$ hypothesized that IT might be used to increase integration between departments and thus reduce the level of interdepartmental competition. Mann and Williams (1960) and Whisler (1970a) note a related effect. In some cases, low level workers in different departments can not simply work out a solution to some shared problem, as they might have in the past, because their results must lit an often inflexible information system Instead, intervention by higher levels of management and by the data processing staff is required, thus increasing centralization.

Economies of scale Another reason to centralize is to take advantage of economies of scale. In general, as a functional group grows, it becomes more efficient in production, since it can take advantage of economies of scale and share capacity between the different parts of the firm that require its services For example, a centralized copving center can realize several advantages. First, since it does more copying, a central serukt can purchase paper and other raw materials in bulk and buy larger and more efficient copiers. Since the service is shared between many users, there is less 
variation in the load, so each machine can be used more efficiently. Furthermore, the service can afford to buy more specialized, but less frequently used equipment and train people in its use These increased efficiencies are offset, however, by the increased cost of coordination, both within and between groups For example, to get service from such a centralized copving plant might require filling out a requisition, arranging for billing, delivery, etc., increasing the service time. Rush service might be difficult or expensive to negotate Furthermore, the central service will need a manager. and perhaps other administrative personnel to ensure its smooth operation. If each department had its own private copier, many of these costs would disappear. Increased use of IT may reduce the cost of the necessary coordination, thus favoring increased centralization. A shift to functional hierarchies is noted by Scharek and Barton (1975) Whisler (1970a) reports the replacement of departments selling different types of insurance with functional departments performing specific tasks for all policies. Osterman (1986) and Rice (1980) both discuss the use of task pools for word processing or routine clerical operations, another form of functional specialization. Malone and Smith (1984) and Malone (in press) present a simplified model of an organization based on the information processing necessary to coordinate the assignment of tasks to different agents within the organization. Ling this model, they identify tradeoffs between different organizational structures based on their production and communication costs and robustness of the organization in face of the failure of agents Malone and Smith (1984) show how this model is consistent with the historical development of American tirms (e.g, as discussed by Chandler (1962)) and argues that as the use of IT decreases coordination costs, the tradeoff shifts in favor of functional hierarchies

As the cost of coordinating decreases further, hovever, more decentralized organizational forms such as markets may become desirable 1. Malone and Smith. 1984) Markets are assumed to have lower production costs, since they can iurther exploit economies of scale and average uncorrelated demand across many tirms, but higher conedination costs, since more communication is necessary to tind a 
supplier, and contracting with an outside party involves higher levels of risk and uncertainty As the cost of coordination drops, however, these factors become less important. Malone, Benjamin and Yates (1987) argue similarly that the use of IT may lead to the increased use of markets and especially of computer mediated markets, which may offer more efficient coordination.

The use of IT may also allow physical decentralization of work. Many organizations are already geographically dispersed and courdinated using telecommunications. Olson (1982) suggeits that "telecommuting" may allow individuals to work at home instead of at a central office. Becker (1986) presents a number of arguments against home work, and suggests satellite work centers instead.

\subsubsection{Motivational and political reasons}

Another commonly discussed possibility is that centralization of decision making is inherently desirable to managers, and decentralization takes place only because no single person can control the necessary resources le $g$, information, employees) due to limitations in human information processing capacity (Simon, 1957). These constraints force managers to delegate control over some decisions in order to focus on more important issues (Schultz and Whisler, 1964). The use of IT may lessen these constraints in two ways. first by providing easier access to and facilitating more complete analyses of data about the operations of the hirm, and second by providing a mechanism to program jobs and to control workers. The use of IT may thus permit decisions to be made at a higher level and ensure their implementation by subordinates. Leavitt and Whisler (1958) and Pfeffer (1978) both suggest that IT can make centralization possible and that firms will therefore recentralize. As Zuboff (1983a) points out, it may often be difficult for a manager to have data about a problem and refrain from acting on it.

Alternately, a manager might want io encourage decentralization of decisions to increase worker autonomy which may be desırable hr rea-uns discussed below). Some authors have predicted that IT 
will encourage greater participation in decısions by lower level workers. IT provides ways to control the premise of the decision, by allowing more equal access to data or by controlling the way in which a decision is made, and to monitor the results, by providing quicker feedback. Given the ability to ensure that decisions are made consistent with their wishes, managers may be willing to delegate the actual decision. Systems used to provide individual support may also encourage decentralization, as they increase an individual's capacity to analyze data or enforce the use of common decision analysis tools. IT can also support lateral ties between low level workers, allowing them to more easily exchange information and thus coordinate their own activities, as suggested by Galbraith (1974, 1977) and found by Robey (1981).

\subsubsection{Other structural features}

\subsubsection{Differentiation}

Another possible impact of the use of IT is the development of increasingly differentiated or segmented jobs. Differentiation is difficult to define or measure precisely Researchers in this area have measured, for example, the number of job titles used in a given organization or the number of different departments. It seems certain that the use of IT will require some new jobs and departments, such as a data processing or telecommunications group, if only to manage the complex technology. Carter (1984), for example, found that the use of $1 \mathrm{~T}$ in newspapers did lead to the creation of new specialties. such as data processing manager. It is less clear how the use of IT will affect other functions in an organization. Earlier, we argued that IT could lead to a reintegration of some tasks le.g, handling all aspects of issuing a letter of credit, Instead of a single step in a multi-step process (.Mateis, 1979)). Such a reintegration would reduce the differentiation hetween jobs or departments Alternately, an increased level of functional specialization could increase the degree of differentiation. The empirical 
evidence is mixed. Mohrman (1982) cites some evidence that technology reduces differences between different roles, while other researchers (e.g., Carter, 1984) report an increase.

\subsubsection{Formalization}

IT is often hypothesized to affect degree of formalization of organization Here formalization refers to the degree to which the organization depends on formal rules and regulations in operation. An informal organization, sometimes called an organic organization, is one in which few rules and formal procedures are used For example, companies with production lines often have rigid work rules, while most research laboratories are administered based on individuals' interactions and not formal rules.

The use of IT can affect the level of formality in an organization in many ways. Most older centralized transaction processing systems are inflexible. Since the systems can only do things in one way, rules are needed to limit actions to this process. The system itself embodies many rules about how the job should be done, again substituting the use of rules and regulations for individua! decision making. A system may also make it easier to spot errors and identify their sources, thus further controlling work (Mann and Williams, 1960) On the other hand, Pfeffer (1978) points out that the use of IT may encourage the evaluation of outcomes instead of process, and make enforcement of rules both easier and less necessary by providing of quicker feedback about the outcomes of actions, thus decreasing formality. Finally, since smaller organizations are typically less formal, IT may decrease formality by reducing organizational size. For example, Woodward (1980) found that heavily automated manufacturers, such as oil refineries, had few actual production workers, thus reducing the level of formality among the remaining. mostly manageria! or professional workers.

The use of IT for individual support of in communications may well have different effects On the one hand, Olson (1982) notes that using teiecummunications to allow workers to work at home resulted in 
less personal interaction and therefore more formal evaluations. On the other hand, both Foster and Flynn (1984) and Pfeffer and Leblebici (1977) found that the use of IT could lead to less formalized interactions. Culnan and Markus (in press) cite research that showed how the use of electronic mail could undermine the formal hierarchy, again suggesting a decreased level of formality Huber (1984) suggests that as informal processes or "soft" data become more important for organizations, these organizations may become more formal about ensuring their esistence.

\subsection{Information Processing Perspective}

One problem with classic organization theory is that in its focus on organizational structure, it does not address what IT is particular useful for, namely, processing information. A potentially very useful way to examine the impacts of IT on organizations is to examine the kinds of information the organization uses and the ways it processes this information (Galbraith, 1974, 1977. Tushman and Vadler, 1978). Tushman and Vadler (1978: 292) outline three basic assumptions of such an information processing perspective organizations must deal with work-related uncertainty: organizations can fruitfully be seen as information processing systems: and organizations can be viewed as composed of sets of groups or departments. In this view, organizational structure is the pattern and content of the information flowing between the subunits and the way they process this information.

\subsubsection{Patterns of communication}

IT can affect the pattern and content of organizational communications in many ways. First, the use of IT may lead to changes in the structure of an organization. leading to new patterns of communication or changes in the content of quantly of existing kinds of communication Integrating jobs, a pussible outcome of the une of IT. could leud to reduced reeds for communation since a single 
person could do the job with no need to communicate with co-workers, an effect noted by Whisler 1970b). For example, storing transaction data in a commonly accessible data base may make requests for information unnecessary. Such changes may also affect the level of social interactions that people experience. Some researchers claim that by integrating tasks, the use of IT eliminates the need and opportunity for workers to interact. For example, Crawford (1982), in a study of use of electronic mail, noted a decrease in the amount of face-to-face communication Zuboff (19s.3b) hypothesized that social isolation will be further increased if workers can work at home instead of in an office. On the other hu.ld, Foster and Flynn (1984) found that the use of IT can lead to increased personal contacts. suggesting that different uses of IT will have very different effects

Second, IT may be used to provide new media for communication, such as electronic mail or computēr conferencing, again leading to new patterns of communication. These kinds of systems have been somewhat more heavily studied, and a number of important characteristics of these sistems have been identified For example, computerized media might be preferable to other kinds of communication because it is potentially faster and cheaper (Crawford, 1982). Furthermore, computerized communications has a low incremental cost per message, that is, it costs the sender about the same to send a message to 1 person as it does to 2: if the systems supports mailing lists, it may be as easy to send mail to hundreds of people. specifving only the name of the list. Crawford (1982) notes that this form of bulk mailing eliminates the need for secretaries to duplicate and mail multiple copies of memos. Finally, electronic mail or conferencing are asynchronous: only one of the recipients needs to be present at a time, making communications easier to arrange (e.g., across time zones). By thus reducing the cost of communications, IT may make coordination less expensive. with the possible results discussed above. Huber (1984) iuggests that such uses of IT will be necessary to allow: organizations to deal with the more cumplex and more turbulent post-industrial environment, with more available information. 
The ability to address communications by other than the name of the recipient le $g$, to a mailing list for electronic mail, or to a specific conference for computer conferencing) means that a sender might not know the person with whom he or she is communicating, but only the area of interest. Computers could be used to better support this sort of communication. For example, the Information Lens system (Malone, et al., 1987) is designed to help users of an electronic mail system get more of the information they are interested in and fewer unrelated messages.

\subsection{Weaklinks}

By providing new communications channels, computerized media may facilitate the formation of "weak" (acquaintance) ties. For example, Freeman (1984) studied use of computer conferencing by scientists and found that people became aware of each other and each others' work even though they had not met in person, and suggested that the computer system allowed these contacts to develop more easily. Easier formation of weak ties may also lead to a shift from hierarchical to "all-channel" communications in companies. Some studies have shown an initial increase in vertical communication, followed by a shift to more evenly distributed communications as new horizontal links are formed and the formal reporting system begins to decline in (relative) importance 1 Culnan and Markus, in press). (Interestingly, similar results have been noted for the introduction of the telephone, which provided comparable improvements over prior communications media.) Weak links can be valuable new sources of information (Feldman, 1986). C'sers of electronic mail in two studies reported that as many as 60\% (Culnan and Markus, 1986) or 70\% (Sproull and Kiesler, 1986) of the messages they received were messages that they felt they would not have got from another source and $50 \%$ of the messages they sent were sent to people with whom they would otherwise not have communicated. Some of this new informaton may he unnecessary, contributing only to computerized junk mail. In the wo studies, much of the res intormation was not work related Some of it, however. 
Included valuable data that were difficult or time-consuming to collect in any other way, such as users' opinions of proposed changes in system features.

\subsubsection{Social context cues}

Computerized media currently provide fewer social context cues than do many other kinds of communication media. These cues regulate many kinds of interaction, and their ahsence may change the nature of computerized communications. Since the recipient may know only the sender's name, and the sender may know nothing at all about the recipient, cues such as age, sex, race, appearance or status may be eliminated Computerized media, in their current text only format, provide only a limited bandwidth channel. This limitation eliminates subtler kinds of communications such as body: language, tone of voice. etc. Finally, since man! kinds of computerized communications are asynchronous, users are deprived of any feedback as they communicate. (lt should be noted that none of these limitations are unique to computerized communications: written memos are also asynchronous and text only, and may be written without knowledge of all possible recipients.) Sproull and Kiesler (1986) claim that this lack of social context cues leads to less inhibited communications, which may have positive or negative effects. For example, people may be more willing to speak out over an electronic system that preserves some anonymity than in a public meeting and what they say. may be considered more seriously. On the other hand, they may also engage in more expression of extreme opinions ("flaming") (Kiesler, Siegel and McGuire, 19841.

\subsection{Motivational Perspective}

The perspectives discussed in preceding sections capture many important aspects of coordinating the activities of people in organizations but they may leave out some of the most important factors about why people are there in the first place 
Some factors that affect motivation and satisfaction at work, such as pay, henefits, or working conditions, are primarily extrinsic to the tasks being performed. Hertzberg (1968) hypothesized that these "hygiene" factors may lead to dissatisfaction if they are below some acceptable level, but that they are not positive "motivators" for greater effort. In other words. these extrinsic factors may affect which goals people choose and whether they choose to participate in the organization at all (e.g., see Warch and Simon, 1958, chapter 4 ), but these factors alone would not usually lead to highly involving and satisfying jobs.

Another set of factors, however, are intrinsic to the tasks being performed and they seem to be particularly important in determining the degree of involvement and satisfaction in an activity le $g$, see Hertzberg, 1968) We divide these factors into two groups. 1) individual motivations that may be present in any activity, and 2 ) interpersonal motivations that depend for their appeal on interactions between people. Even though there are no firm conclusions about the overall consequences of IT for these motivations, Attewell and Rule (1984) note that a number of previous surveys show more cases of increased rather than decreased job satisfaction after the introduction of IT.

\subsection{Individual motivations}

Malone (1982) discusses a number of suggestions for how individual motivational factors such as challenge, fantasy, and curiosity can be used to make user interfaces more interesting and enjoyable. For example, for some users challenge can be enhanced by incorporating successive layers of complexity in an interface with each layer being mastered in turn as users become more skilled. When we expand our focus to include designing systems to be used by groups of people, it becomes clear that computers make it possible and snmetımes desirable to redesign whole jobs and organizations, as well as individual programs Hackman and ()ldham 1980) suggest five factors that contribute to highly motivating work Shall eariety, lavk dentubli, doing a whole job, rather than a piece of onel and task 
significance are hypothesized to contribute to experienced meaningfulness, autonomy to experienced responsibility and feedback to knowledge of actual results Workers whofeel they are responsible for a meaningful job and who can tell how well they are dong it are believed to be more motivated to do well. These factors are related to the four suggested by Walone. for example, the concept of "skill variety" in well designed jobs can be seen as another way of increasing the challenge of a job. We will discuss the possible effects of IT on skill variety, task identity and significance and autonomy

\subsubsection{Skill variety}

Deskilling One particularly common prediction of the effect of IT is deskilling. IT can be used to strip a job of its content, leaving only a dull routine. For example, instead of directly solving some problem, a worker might instead feed the relevant data to a computer and have it solve the problem. This approach may have some advantages for the organization, since it assures a more consistent solution to the problem, but the resulting job may be less desirable for the worker

Schultz and Whisler (1964) suggest that computers can replace lowest level clerical and analytic functions, displacing an employee if that was all the person did. Clertis are still needed to prepare data for the computer, but these new jobs may have lower skill requirements than the jobs they replace. Glenn and Feldberg (1977) describe this process as the "proletarianization of clerical work". They note that clerical jobs are becoming more like factory jobs, with increased subdivision of work and specialization of workers due to automation and use of scientific management principles from classic organization theory as management attempts to control workers and reduce the variability of their output. Similar deskilling has been noted by. Mann and Williams (1960), Whisler (1970b) and Scharek and Barton (1975). As the now of work hecomes more like an assembly line, an individual clerk's pace hecomes regulated hy needs of procezies on either side and the need for interaction and resulting opportunity for social ties to torm are reduced 
Zuboff (1983a) points out that a system embodies assumptions about how the work should be done, resulting in a loss of flexibility for the worker. The system may also decrease the ambiguity of work, reducing workers' opportunities to display their mastery of their jobs. Formal rules replace discretion or specific knowledge, thus reducing inner motivation to work. Many of these effects may also apply to jobs of middle managers As computers are used to handle more and more analyses, middle managers may be reduced to messengers or eliminated altogether

Upgrading. The opposite prediction is upgrading. Instead of doing the job that the worker did, computers could be used to automate the repetitive parts, leaving more interesting components for the human, and producing a more desirable job requiring a higher level of skills or having more responsibilities. For example, Zuboff (1983a) presents a case in which the automation of a paper mill increased the role of the first line production workers since they could control more than the single functions they used to. The jobs therefore required more skill, and the operators began to perform some of the functions of the managers. Mann and Williams (1960) also found some cases of job enlargement and that the system eliminated many routine jobs.

The use of IT may also upgrade the jobs of middle managers. Instead of simple collecting and presenting data, managers will be able to analyze and interpret data. Their role may change from giving orders to convincing others of their interpretations. Argyris 11970 ) hypothesized that managers would have to be better educated to deal with increased flow of data.

Deskilling and upgrading. In practice, both effects seem likely to occur simultaneously. Attewell and Rule (1984) report both deskilling and upgrading, and note that it is difficult to determine which predominates. They present some evidence that there are now more skilled johs and fewer unskilled Dnes. but point out that it is hara in determine the cause for this shift. They conclude that the studies that have been done have not betn wry wil designed, again making firm conclusions difficult. 


\subsection{Task meaningfulness}

The category of task meaningfulness refers to Hackman and Oldham's notion that jobs are more satisfying when they involve the completion of a "whole" and identifiable piece of work ("task identity") that has substantial impact on the lives of other people ("task signilicance") In computer games and in some unavoidably dull jobs, it is possible to use fantasy to increase the meaningfulness of an activity te.g, the task of controlling a factory process can be mapped into a fantasy display of piloting a space ship (Carroll and Thomas, 1980)). However. the implication of this category name is that organizational use of computers should be designed to make the tasks themselves as meaningful as possible. For example, one of the reported benefits of an early office automation project was that bank clerks had their jobs restructured so that the no longer performed isolated clerical steps in a process they did not understand, but instead handled all the steps in dealing with their assigned customers (.Matteis, 1979: Lorsch, Gibson and Seeger, 1975$).$

\section{3.1.4. Autonomy}

The use of IT can change the degree of autonomy that an individual worker has in doing his or her job. Many researchers believe that computer systems offer new possibilities for supervising and controlling workers (e.g., Briefs, 1981, Zuboff, 1983a: Business Week, 1983). The use of a computer system may make it easier for a worker's superiors to control his or her work (for example, by providing quicker feedback about a worker's performance) and make it clear who is not performing Blau et al. (1976), however, find increased control only in routine jobs.

Increased control by supervisors Argyris (1970) suggests that a centralized information system may reveal previously hiditen information. roducing an emplovee's perceived freedom to act, and mating the system threatening Zubuff 1933 a urgucs :imilarly that since the system makes information 
more widely available, a subordinate may become less willing to act independently on data that his or her superior will also see

Increased control by system A system may also become itself an impersonal source of authority (Zuboff, 1983a). One form that such a loss of autonomy can take is when the computer system takes control of the pace of work and determines how quickly the work must be done Zuboff (1983a) suggests that computer gives quicker feedback, thus increasing pace of work, even if it is not set explicitly. This view was argued by Foster and Flynn (1984), who suggest that IT used to automate routine functions may thus allow more time for thinking about the task to be done. Attewell and Rule (1984) report mixed findings on this topic $25^{\circ} \mathrm{c}$ of the studies the surveyed reported an increase time pressure; $50^{\circ}$, no change: and $25^{\circ}$, a reduction in time pressure

Increased autonomy for uorkers. A system could also have the opposite effect. As noted above, for example, automating the routine parts of tasks could allow reintegration of several previously separate jobs, resulting in a job that can be done independently and without direct supervision. Managers may also be more willing to delegate responsibility, since their subordinates' results can be tracked by the system.

Walton (1982) provides examples of both increased control and increased autonomy, and points out that the designers of systems have a choice in how the technology is used. Attewell and Rule (1984) summarized a number of studies by noting that most workers do not report an increase in perceived control or in their control over their subordinates. but that feelings of control and being controlled increase at higher levels of the hierarchy Kling (1980) also reports that the use of IT seemed not to radically change the nature of work, for workers he studied.

\section{Interpersonal motications}


When we are concerned with group interactions, three kinds of interpersonal motivations (cooperation, competition and recognition) can be as important as individual motivations (see . Malone and Lepper, in press). Systems can be designed to engage these interpersonal motivations For example. one of the problems that may arise in a text-sharing system is how to motivate people to contribute information. In addition to economic pricing schemes, intrinsic motivations may be used for this purpose. For example, people's motivation for recognitiun might he engaged by a system in which rankings of the most widely read messages in different categories can be displaved along with their authors' names. This approach should be even more effective if messages that are rated by some readers as being very valuable are then automatically redistributed to d wider audience.

\subsection{Political Perspective}

A central construct for political analyses of organizations is power. A political view sees the organization as composed of shifting coalitions that compete for resources. Power can be loosely defined as the ability of one person or group to influence the actions of another (Bariff and Galbraith, 1978). Power has many sources, such as the "legitimate" authority of a superior in a hierarchical organization, the promise of rewards, the control of access to necessary resources (perhaps including information) or expertise. Other measures of a group's power include work flow pervasiveness (the number of other groups that depend on this group), immediacy (how quickly the loss of a group's services is felt) and substitutability (the extent to which some other group can substitute for this one).

The use of IT affects the distribution of power in many ways First, IT affects access to information, a potentially vervaluable resource In some settings, it is possible that IT will be used primarily for its $\because y$ mbolic value, rather than for any particular functiunality. making the IT itself a potential resource (Feldman and March, 1981$)$ Second. IT affects how people do their job. aygan changing the nature of the relationship between groups One (likely) possibility is that IT will be used largely to reinforce the 
existing power structure of the firm. for if it did not, power holders in the organization would be unlikely to encourage its use (Kling, 1980: Pfeffer, 1978). It also seems clear that use of IT can greatly increase the power of those who control it (Pfeffer, 1978). We will examine two different distributions of power vertical (ce, between levels in the firm), and horizontal (c.e, between groups at the same levell.

\section{Vertical distribution of power}

One way IT can affect the vertical distribution of power in a $7 \mathrm{rm}$ is by changing who has access to information. For example, a computer system may provide an easier way to monitor the results of subordinates actions and to speed the flow of information upwards in the company, thus centralizing power. For example. Leavitt and Whisler 1958 ) noted that in companies with computer systems, the junior managers no longer controlled which information was summarized and reported. Similarly, Zuboff (1983a) found that managers of automated plants felt that they no longer controlled information about production and so lost power. Before the introduction of a computer system, for example, the plant managers chose when and how to report problems the plant experienced; with the system, they found out about them at the same time ds everyone else did. Many systems may encourage this process, since they are often designed primarily to meet the needs of managers. For example, Grudin (1987) points out that multi-user systems may require many people to work with them, while benefiting only the manager

IT can also be used to decentralize. thus moving power down in the organization. For example, a universally accessible data base can reduce top management's monopoly on company-wide informaticn. The use of IT may thus change the basis of power by making information less of a scarce resource. To the extent that vertical power : : nu- equalized, other sources ot power will become more important. One common prediction is that power will he batied on competence and knowledge, rather 
than on hierarchical position (Argyris. 1970: Foster and Flynn, 1984) Zuboff (1983a) found that when the system made more information equally available, power was not telling someone what to do $(\imath e$. based on hierarchical position), but rather convincing them to accept your interpretation of the data Attewell and Rule (1984) reported that most studies find either no change or a reinforcement of the existing power structure, although they note that the use of IT seems to be "compatible with a wide variety of lateral and vertical power relationships in organizations" (Attewell and Rule. $198+1189$ ).

\section{Horizontal distribution of power}

The use of IT can also change the balance of power between groups at the same organizational level of a firm. For example, a common computer system may lead to greater data sharing and thus power equalization between groups at the same level. This cooperation could then lead to greater coordination, allowing better performance, since the two groups could jointly optimize rather than each trying to do the best it can individually.

As mentioned, use of IT can greatly increase the power of the group that controls the technology. IT may become critical to the operation of the firm: most banks, for example, would be completely unable to function if their computer systems failed. The group controlling computer systems may also control access to data, a potentially scarce resource. The IT group may be in a position to mediate between other groups, for example, by setting corporate standards for computer equipment or software, thus defining the functionality available even to users of personal computers. Schultz and Whisler (1964) suggest that these staff members dssume some of the functions of the line managers, and that they therefore should be tied to top management and to the strategic goals of the firm.

\section{Implications for further research}


Our review of the literature has revealed several shortcomıngs that should be addressed by further research. First, it is clear that the field needs better conceptualizations and operationalizations of the two major dimensions: technology and organization. Until there is better agreement on the meanings of these central terms, it will be very difficult to compare and integrate different pieces of research. Typologies of technology and organization may also serve other functions, for example, by suggesting relationships that have not been adequately studied

The perspectives we have discussed suggest appropriate variables to investigate and provide theories of likely kinds of interactions as well as methodologies to investigate them. For example, we believe that one of the most important characteristıcs of IT is that it processes information, and that analysis of the kinds of information an organization uses and the wavs the information is processed provides considerable insight into organizational functions, as well as a basis for the design of systems.

Second, the field needs better research design. As in any social science, cause and effect are complex. There are a great many possibly important variables, and it is difficult to identify which are most important and to control the rest. Simple correlational studies are inadequate because they omit too many possible significant variables and relationships and designers should be cautious about making generalizations from such studies In general, it seems premature to concentrate on only a few variables. In the short run, this may mean an increased use of methodologies such as case studies that emphasize understanding at the expense of generalizability. Most importantly, we need to be able to identify the implications of the use of IT and provide guidance for the designers of systems. Malone (1985) suggests a change of focus from explanatory or predictive theories ( $i$ e. if $X$. then $Y$ ) to theories

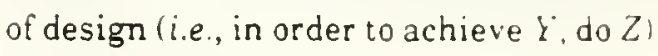

\section{Implications for the Design of Systems and Work}


As we have seen, there appear to be few inevitable results of the use of IT and very many possible outcomes, depending on factors such as the organizational context, the type of IT used, management motivations and so forth. Since no general theories exist for predicting the outcomes of particular situations, our primary advice to designers is simply to use the frameworks and examples presented above to consider more explicitly in advance possible outcomes of the use of IT

Walton (1982) points out that past studies of the implementation of computer systems have often focused on ways to overcome resistance to a new system. He argues that these efforts should be extended to the design phase as well, to aroid, rather than merely overcome potential problems. He notes (Walton and Vittori, 1983) that even though managers seem to realize that the use of IT can have organizational side effects, there is little effort to predict or reduce them. Walton suggests first that organizations need explicit normative models, stating what kind of effects are desirable. New systems should be explicitly assessed for their organizational impacts and the design process should allow the systems to evolve as the nature of their impacts change or become clearer. Each individual or group within an organization may judge systems differently, however. One issue for a designer, then, is to determine the clients of his design, that is, whose value systems will be used to guide the design.

In the remainder of this section, we will briefly suggest how the four perspectives we discussed above suggest principles for designing systems, work and organizations

\subsection{Rationalist perspective}

The rationalist perspective assumes that the organization has an identifiable goal. such as profit maximization, and that IT should he used to achieve that goal mure efficiently, for example, by reducing costs or increasing the qualıty of the output This can be done by analyzing the functions of 
different parts of the organization, and automating where it is cost-justified to do so. Since much current systems design attempts to follows this perspective, we will not discuss it further, except to note that for systems used for coordination it may be difficult to identify inputs and outputs or to place a value on them, making cost-justirication problematic (Crowston and Treacy, 1986)

\subsection{Information processing perspective}

In the information processing view. IT has 4 major effect by providing cheaper coordination, thus making coordination intensive forms more practical. A company might take advantages of economies of scale by creating larger functional departments, using IT to provide the necessary coordination between different groups For example, different divisions of a company could all use data stored in one centralized database, rather than each having partial information or passing information between themselves. Alternately, a company could use market-like structures, again coordinated by the use of IT. Airlines, for example, now provide an electronic marketplace for selling tickets.

Systems like electronic mail or computer conferencing may have several advantages. First, they may be a more efficient media for existing communication: faster, asynchronous, and possibly less expensive. Second, electronic media may lead to new patterns of communication. either encouraging people to participate more actively, or helping form weak links, which can provide new data Systems like the Information Lens (Malone et al, 1987) may be used to help process quantities of semi-structured data.

Work redesign could be based on the "object-oriented" modeling technique discussed by Crowston, Malone and Lin lin press) The resulting model of the organization may reveal places where the intirmation llow can be streamlined or where IT can be used to hetter support the necessary 
processing Possible organizational structures for a glven task can be compared by estimating the cost of different kinds of communications links, to determine which will be the most effective.

\subsection{Motivational perspective}

In the motivational perspective, the client of a new information system is the workers, and only indirectly the organization. A successful design will be one that increases worker satisfaction and improves attitudes towards work

A motivational design might start by analyzıng the costs and rewards of a job for the individual holding it. Hackman and Oldham (1980). for example, provide an instrument that attempts to measure the motivating aspects of a job They also suggest characteristics of an organization that should be checked to assess its readiness for changes If the conditions are such that a work redesign is likely to fail, or to have little effect, they suggest that it not be attempted

Sirbu (1980) offers several suggestions for software design that increase the motivating aspects of users' jobs. He suggests that rather than enforce restrictions on users' actions, designers provide mechanisms to hold them accountable for what they do, thus increasing autonomy. To increase feedback, Sirbu suggests that any monitoring reports generated be shared with the users, not restricted to their managers. Finally, he suggests that systems provide opportunities to master new skill and perform new tasks, thus increasing shill variety.

A design methodology that attempts to create motivating work is socio-technical design. Socio-technical design attempts to simultaneously 1 mprove the social and technical subsystems of a job in order to achieve the most effectue foh desın. Pava (1983) provides a good introduction to this technique and discusses its applications to the design of information systems 


\subsection{Political perspective}

The political perspective suggests that it is important to explicitly determine the client of a design, since different groups will have possibly conflicting goals and value systems. It may be useful, therefore, to secure support from an existing power holder, such as top management A designer should also attempt to analyze the existing power structure of the firm to identify vested interests, both for and against the system, which may be at the root of resistance to change Zubolf (1983a), for example, suggests examining carefully any sources of resistance to a new system. She notes that although the immediate complaints may disappear, the underlying problems may continue to adversely affect the work setting inderinitely. Involving users in the design of the system may improve the design of the system by revealing the designers' implicit assumptions about the nature of the problem, as well as improving the eventual users' feelings of ownership of the system.

\section{Conclusion}

One theme of this paper has been that a system designer is an organizational change agent, whether intentionally or not. Designers must be aware that their systems are not neutral objects, but instead reflect a theory of how the surrounding organization does or should work. Furthermore, the impacts of information technology (IT) are not deterministic: similar systems can and do have widely different effects, depending on the particulars of the organization and the intentions of the managers who deploy them. Designers should therefore be explicit about which effects are desirable, and attempt to predict and control the impacts that the system does have.

To understand these potential impacts, we need to understand organizations, technology and the link between the two Cnfortunate!y tne hody of thenry in these areas is neither well developed nor 
integrated Indeed, different researchers approach these topics from different perspectives. often arriving at contradictory findings, or simply talking past each other

Each of these perspectives provides only a partial view of the relationship between organizational structure and information technology, however, and designers should be cautious about predictions that acknowledge only one view When a system is viewed from all these perspectives, design can begin to predict and to design the effects of their systems on wortiorganization 


\section{Bibliography}

Argyris, Chris. Resistance to Rational Management Systems. Innouation, Number 11, 1970 28-35.

Attewell, Paul and Rule. James. Computing and Organizations What We Know and What We Don't Know. Communications of the AC.M, Volume 27, Number 12, December 1984: 118+1192.

Bakos, Yannis. Toward a More Precise Concept of Information Technology. In Proceedings of the Sixth International Conference on Information Systems L. Gallegos (Ed.), Indianapolis, Indiana, December 16-18, $1985 \quad 17-21$

Barett, S. and Konsynski, B Inter-Organization Information Sharing Systems. MIS Quarterly, Volume 6, 1982: 93-104

Bariff, Martin L and Galbraith, Jay R Intraorganizational Power Considerations for Designing Information Systems. Accounting. Organızations and Society, Volume 3, Number 1, 1978: $15-27$.

Becker, Franklin D. Loosely-coupled Settings A Strategy for Computer-aided Work Decentralization. Research in Organizational Behavior, Volume 8, 1986 199-231.

Blau, Peter M., Falbe, Cecilia McHugh, McKinley, William and Tracy. Phelps K. Technology and Organization in Manufacturing Administrative Science Quarterly, Volume 21, March 1976: $20-81$

Briefs, Clrich Re-Thinking Industral Win Computer Effects on Technical White-Collar Workers. Computers in Industry, Numbel:- $19=1$ ih-81 
A New Erafor Management Business Week, April 25, 1983 50-86

Office Automation. Business Week, October 8, 1984. 118-142

Carroll, I . II and Thomas, J C . Metaphor and the cognitice reprosentation of computer systems Yorktown Heights, NY IB.M Watson Research Center technical report number RC8302, 1930.

Carter, Nancy .H. Computerization as a Predominate Technology. Its Intluence on the Structure of Vewspaper Organizations. Academy of Management Journal, Volume 27. Number 2, 1984 $247-270$

Chandler, A. D Jr. Strategy and tructure Chapters in the history of the American industrial enterprise. Cambridge, M.1. .IIT Press. 1962

Child, John. Organizationa! Design and Performance Contingency Theory and Beyond. ?

Crawford, A. B Jr. Corporate Electronic Mail-A Communication-Intensive Application of Information Technology, MIS Quarterly, September 1982:1-13

Crowston, Kevin and Treacy, Michael E. Assessing the Impact of Information Technology on Enterprise Level Performance. In Proceedings of the Seventh Annual Internattonal Conference on Information Systems, San Diego, CA: December 1t-17, 1986.

Crowston, Kevin, Malone, Thomas $W$. and Lin. Felix Cognitive Science and Organizational Design: A Case Study of Computer Conferencing Human Computer Interaction, in press.

Culnan. Mary J and Markus, .M Lynne Information Technologies: Electronic Media and Intraorganizational Communications In Jabin. Frederic, Putnam, Linda, Roberts, Karlene 
Interdisciplinary Approach, Beverly Hills: Sage Publications, in press

Feldman, Martha S. Constraints on Communication and Electronic Messaging In Proceedings of the CSCW $\$ 6$ Conference on Computer-Supported Cooperatue Work. Austin. TK. December 3-5. 1986: $73-90$

Feldman, Martha S, and March, James G Information in Organizations as Signal and Symbol. Administrative Science Quarterly, Volume 26, 1981 171-i86.

Foster, Lawrence W. and Flynn, David .M. Management Iniormation Technology: Its Effects on Organizational Form and Function. .MIS Quarterly, December 1984, 229-235

Freeman, Linton C. The Impact of Computer Based Communication on the Social Structure of an Emerging Scientific Specialty. Soctal Vetworks, Volume 6, 1984: 201-221

Fry, Louis W. Technology-Structure Research. Three Critical Issues Academy of Management Journal, Volume 25, Number $3,1982 \quad 532-552$

Galbraith, John R. Organization Design An Information Processing View Interfaces, Volume 4 , Number 5, . Hav 1974. 28-36

Galbraith, John R. Organization Design, Reading, MA. Addison-Wesley, 1977

Glenn, Evelyn Nakano, and Feldberg, Roslyn L. Degraded and Deskilled: The Proletarianization of Clerical Work. Soctal Probiems. Volume 25, Number 1, Octoher 1977: 52-64 
Grudin. Jonathan Soctal Ecaluation of the Liser Interface. Who Does the Work and Who Gets the Benefit?. unpublished paper, submitted to Interact.

Hackman, J Richard and Oldham, Greg R Work Redesign Reading, MA: Addison-Wesley Publishing Co., 1980 .

Hertzberg, F One more time How do you motivate employees Harcard Business Review, January/February, 1968 53-62

Hirschheim, R. A. The Effect of A Prtorl Views on the Social Implications of Computing: The Case of Office Automation. ACM Computıng Surveys, Volume 18, Number 2, June 1986: 165-196.

Huber, George P. The Design of Post-Industrial Organizations. Management Science, Volume 30 , Number 8, August 1984 928-951.

Kiesler, S., Siegel, J. and .IcGuire, T. W. Social psychological aspects of computer-mediated communication. American Psychologist, Volume 39, 1984: 1123-1134.

Kling, Rob. Social Analyses of Computing: Theoretical Perspectives in Recent Empirical Research. ACill Computing Surveys, Volume 12, Number 1, March 1980: 61-110.

Leavitt, Harold If and Whisler. Thomas L. Management in the 1980's. Harvard Business Review, Volume 36, Number 6, November/December 1958: $41-48$.

Lorsch, J W, Gibson, C. F. and Seeger. J A First. Vational City Bank Operating Group (A, A1, B. Bl). Boston, MA: Harvard Business School Cuse Numbers 9-474-165, 9-475-061, 9-474-166, and 9-475-062, 1975 
Malone, Thomas $W$ Organizing injormation processing systems Parallels between human organizations and computer systems Palo Alto, CA. Xerox Palo Alto Research Center Working Paper, August, 1982

Malone, Thomas W Designing Organizational Interfaces In Proceedings of the CHI 8.5 Conference on Human Factors in Computing Sistems. San Francisco. April 1985.

Malone, Thomas W. Organizational Structure and Information Technology: Elements of a Formal Theory. Working Paper Number 130, Cambridge. WA Center for Information Systems Research, .liassachusetts Institute of Technology, August 1986

Malone, Thomas W Computer Support for Organizations: Towards and Organizational Science. In J. Carroll (Ed.), Interfacing Thought Cognitive Aspects of Human Computer Interactions, Cambridge, .MA: MIT Press, in press.

Malone, Thomas W. Modeling Coordination in Organizations and Markets. Management Science, in press.

Malone, Thomas W, Grant, Kenneth R. Turbak, Franklyn A., Brobst. Stephen A and Cohen, Michael D. Intelligent Information-Sharing Systems. Communications of the ACM, Volume 30 , Number 5, .Hay 1987. 390-402

Malone, Thomas $W$. and Lepper. Mark $R$ Making Learning Fun. A Taxonomy of Intrinsic Motivations for Learning In R E Snow and .H. .J. Farr (Eds.), Aptıtude, learning, and Instruction: III. Conatue and affecture process analysis, Hillsdale. ‥s: Erlbaum, in press.

Malone, Thomas W and Smith. Stephen 1 Tradeoffs in Designing Organizations: Implications for lew Forms of Human Organizations and Cumputer Systems Operations Research, in press 
Malone. Thomas W, Yates, JoAnne and Benjamin, Robert I Electronic Markets and Electronic Hierarchies. Communications of the AC.M, Volume 30, Number 6. June $1987+84+97$

Mann, Floyd C and Williams, Lawerence K. Observations on the Dynamics of a Change to Electronic Data-Processing Equipment. Administrative Science Quarterly, Volume 5. 1960. 217-256.

March, James G and Simon. Herbert A ()rganıalıons Vew York John Wiley and Sons, 1958.

Markus, M. Lynne and Rohey, Daniel Information Technology and Organizational Change: Causal Structure in Theory and Resedrch Management Science, in press

Matteis, R.J The new back office focuses on customer service. Harvard Business Review. Number 57 . 1979: $146-159$.

Mohr, Lawerence B. Organizational Technology and Organizational Structure. Administrative Science Quarterly, Volume 16, 19i1 444-459

Mohrman, A. .1. .Jr The Impact of Information Processing Technology on Office Roles. Paper presented at the annual meeting of the World Futures Society, Washington, DC, 21 July 1982.

Mumford, Enid and Banks, Olive The Computer and the Clerk London: Routledge and Kegan Paul, 1967

Myers, Charles A. (ed). The Impact of Computers on Management. Cambridge, MA. The MIT Press, 1967

lewell. A and Simon Herbert $t$ Computer Science as Empirical Inquiry Symbols and Search. Communications of the AC:H Vi,lumi: 19.1975 113-126 
Nolan. Richard L and Pollock. Alex J Organization and Architecture, or Architecture and Organization. Stage by Stage, Lexington, .MA. Volan, Vorton and Co., Volume 6, Number 5. September-October 1986 . 1-10

Olson, Margrethe $H$ Vew Information Technology and Organizational Culture. .MIS Quarterly. Special Issue, 1982: 71-92

Osterman, Paul The Impact of Computers on the Employment of Clerks and Managers. Industrial and Labor Relations Review, Volume 39, Number 2. January $1986 \quad 175-186$

Pava, C. Managing New Office Technology Sew York: The Free Press, 1983.

Perrow, Charles. A Erameworti for the Comparative Analysis of Organizations. American Sociological Review, Volume 32, 1967: 194-208

Perrow, Charles Complex Organizations . A Critical Essay, 2nd ed. Vew York: Random House, 1979.

Pfeffer, Jeffery. Organizational Design. Arlington Heights. Illinois: Harlan Davidson, Inc., 1978.

Pfeffer, Jeffery. Organizations and Organization Theory Boston: Pitman Publishing, 1982

Pfeffer. Jrffery and Leblebici, Huseyin. Information Technology and Organizational Structure. Pacific Suctological Rev'lew, Volume 20, Number 2, April 1977. 241-261.

Reif. William E. Computer Technology and Management Organizallon. Lowa City, lowa: Bureau of Business and Economic Research, The Lniversity of Iowa, 1968. 
Rice, Ronald E Impacts of Computer. Mediated Organizational and Interpersonal Communication. In 11. Williams (Ed.), Annual Revlew of Information Sclence and Technology, Volume $15 . \quad$ YY Knowledge Industry Publications, 1980

Robey, Daniel Information Technology und Organization Design Lniversity of Wichigan Business Review, Volume 18. Number 6. 1976: 17-22

Robey, Daniel. Computer Information Systems and Organization Structure. Communications of the AC.K, Volume 24, Number 10, October 1981. 679-687

Robey, Daniel. Information Systems and Organizational Change A Comparative Case Study. Systems. Objectues, Soiutions, Volume 3, $1983 \quad 143-154$

Sanders, D. H. Computers in Society. An Introduction in Information Processing Second Edition. New York: McGraw-Hill, 1977

Scharek and Barton. Comments on the influence of information technology on organizational structure in the insurance industry. In Grochla, Erwin and Szyperski, Norbert (Eds). Information Systems and Organıational Structure. Vew York: Walter de Gruyter, 1975.

Schultz, George P. and Whisler, Thomas L. (Eds). Management Organlzation and the Computer. The Free Press of Glencoe, 1964.

Simon, Herbert A. Admınistratile Behalıor Second Edition. New York: The Free Press, 1957

Sirhu. Marvin. Programming Organizational Design In Proceedings of the Fifth International Computer Communication.s Connierence. Atlanta. G.t October, 1980. 
Sproull, Lee and Kiesler, Sara Reducing Social Context Cues: Electronic Mail in Organizationa! Communication. Management Science, Volume 32, Number 11, November 1986. 1492-1512

Stabell, B. B. and Forsund, Finn. Productuty Effects of Computers in Administration: An Exploratory Empirical Investigation presented at the Seminar on the Assessment of the Impact of Science and Technology on Long-Term Economic Prospects. Lnited Vations. Economic Commission for Europe, Rome, Italy, 16-20..Iay 1933

Tausky, Curt. Work Organizations: Major Theoretical Perspectues. Itasca, IL F. E. Peacock Publishers, 1970

Tushman, M. and Vadler, D Information Processing as an Integrating Concept in Organization Design. Academy of Management Revew, Volume 3, 1978: 613-624.

Walton, Richard E. Social Choice in the Development of Advanced Information Technology. Technology in Society, Volume +, 1982: $+1-49$.

Walton, Richard E and Vittori, Wendy Vew Information Technology Organizational Problem or Opportunity? Office: Technology and People, Volume 1: 2ł9-273, 1983.

Whisler, Thomas L. The Impact of Computers on Organizations. New York: Praeger, 1970a

Whisler, Thomas L. Information Technology and Organizational Change. Belmont, CA: Wadsworth, 1970b.

Wilson. Diane. The Reinuention of. Hicrocomputers: Toward an Analytical Framework L'npublished doctoral dissertation. Camhridge. Mt Harvard Lniversity. 1985 
Woodward, Joan Industral Organization Theory and Practice. Second Edition Oxford Oxford University Press, 1980.

Zuboff, Shoshana. Some Implications of Information Systems Power for the Role of the Middle Manager Worting Paper Vumber 3+29, Boston. MA Harvard Business School, May 1983a.

Zuboff, Shoshana New Worlds of Computer-Mediated Wiork Hariard Business Review. September-October 1983b: $1+2-152$ 
Technological Imperative

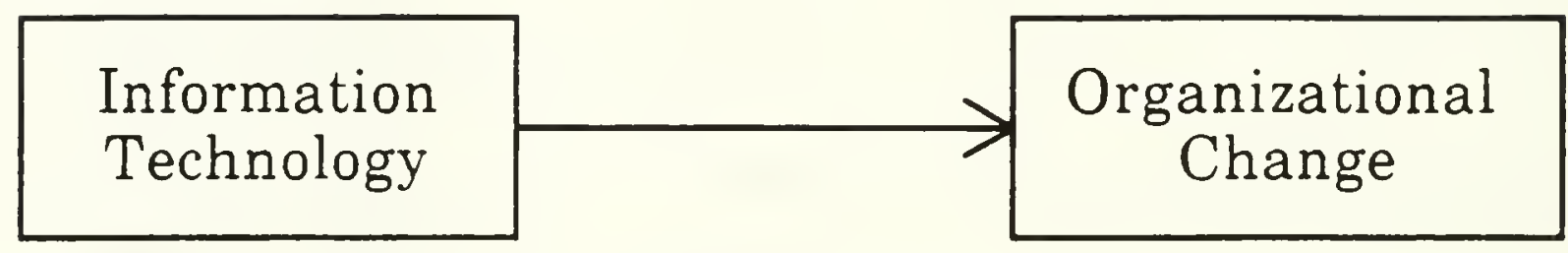

Figure 1 
Organizational Imperative

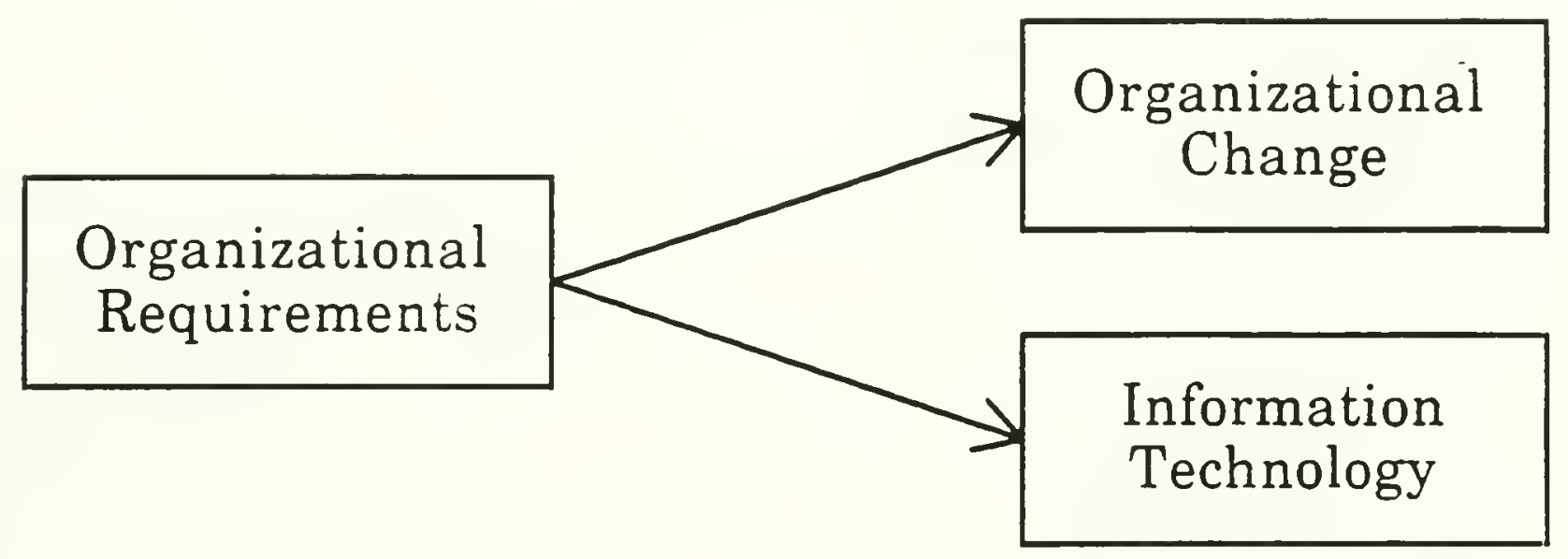

Figure 2 
Interactionist Perspective

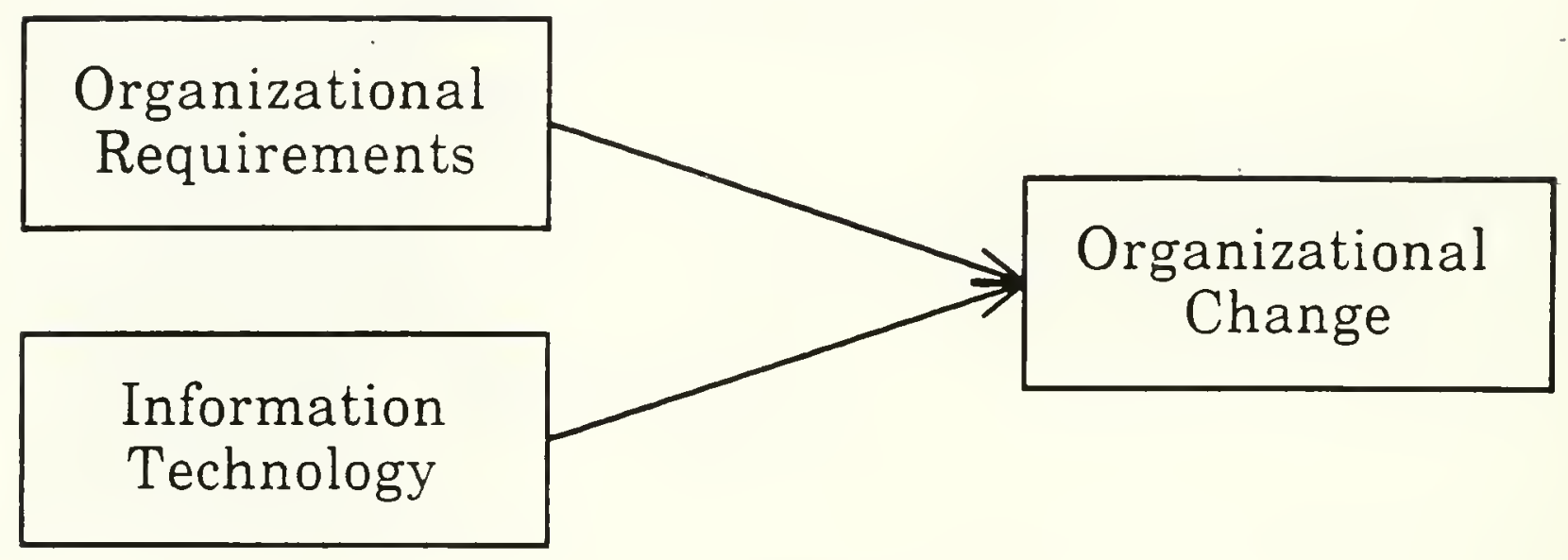

Figure 3 
$39080 \quad 005882433$ 




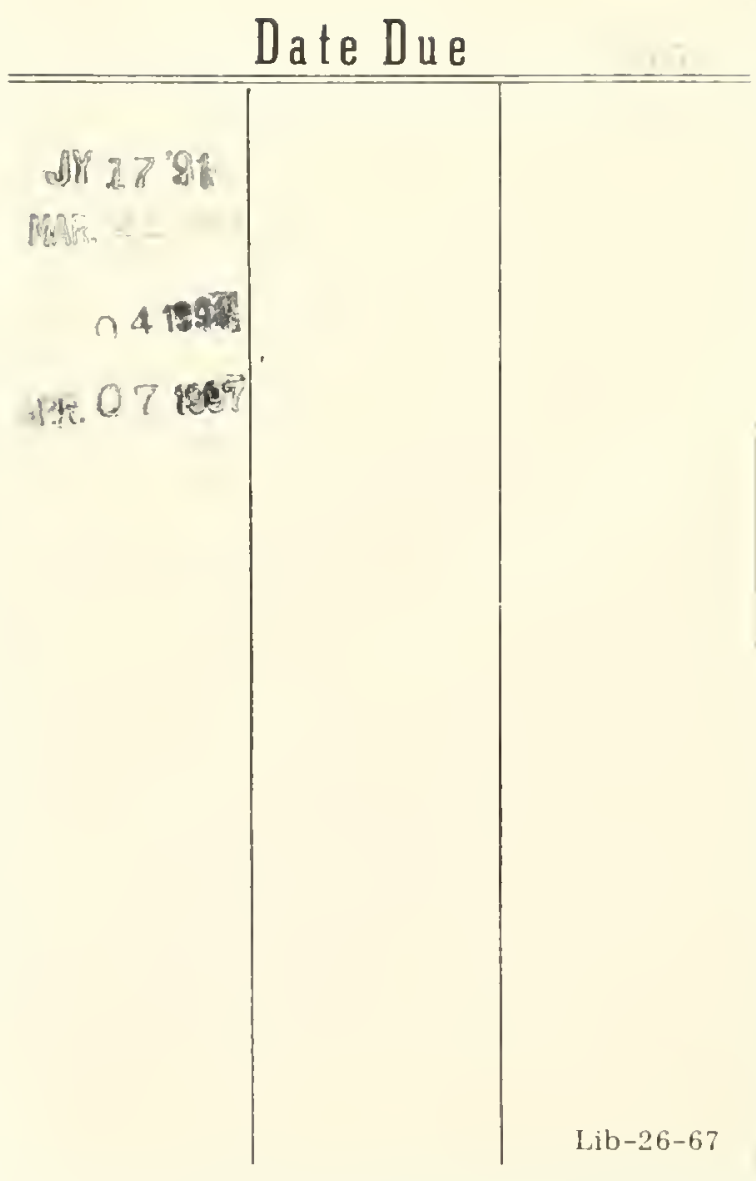




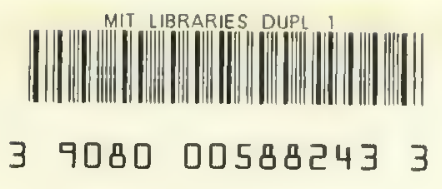


